\title{
Prevalence of dermatophytosis and efficacy of antifungal agents against Microsporum canis in cats
}

\author{
Muhammad Irfan Saleem ${ }^{1,2}$, Asim Khalid Mahmood ${ }^{1}$, Abdul Qudus ${ }^{3}$, \\ Mahboob Akbar ${ }^{4}$, Muhammad Tariq Naveed ${ }^{5}$, Ahsan Nadeem ${ }^{4}$, \\ Muhammad Tanveer ${ }^{4}$, Asia Noor ${ }^{6}$, Muhammad Attique ${ }^{4}$ and Kashif ur \\ $\operatorname{Rehman}^{4 *}$
}

1. University of Veterinary and Animal Sciences, Lahore-Pakistan

2. Livestock and Dairy Development Department, Punjab-Pakistan

3. Cholistan University of Veterinary and Animal Sciences, Bahawalpur-Pakistan

4. Livestock and Dairy Development Department, Poultry Research Institute, Rawalpindi, Punjab-Pakistan

5. National University of Medical Sciences, Rawalpindi-Pakistan

6. University of Agriculture Faisalabad, Faisalabad-Pakistan

*Corresponding author's email:drkashif706@gmail.com

Citation

Muhammad Irfan Saleem, Asim Khalid Mahmood, Abdul Qudus, Mahboob Akbar, Muhammad Tariq Naveed, Ahsan Nadeem, Muhammad Tanveer, Asia Noor, Muhammad Attique and Kashif ur Rehman. Prevalence of dermatophytosis and efficacy of antifungal agents against Microsporum canis in cats. Pure and Applied Biology. Vol. 9, Issue 1, pp121-131. http://dx.doi.org/10.19045/bspab.2020.90015

Received: 26/06/2019

Revised: 24/08/2019

Accepted: 04/09/2019

Online First: 18/09/2019

\section{Abstract}

Dermatophytosis or ringworm is an infectious fungal disease that can be caused by three species of dermatophytes. Microsporum Canis (M. canis) appears to be the most common cause of ringworm. Dermatophytes invade and live in the keratinized layer of the dermis and can be transmitted to humans and animals through direct contact with infected animals or through the ground. The dermatophyte $M$. canis is the most common fungal agent of dogs and cats. The cat is commonly kept as pet all over the world and in Pakistan. The present study noted the prevalence of $M$. canis in pet cats in the area of district Lahore and the chemotherapeutic effect of antifungal agents against the $M$. canis. The animals found positive with $M$. canis were divided into three groups named, group A (griseofulvin), group B (ketoconazole) and group C (terbinafine). All the drugs were given orally, and the efficacy of each drug was observed by collecting the samples on 15 days interval after the commencement of treatment until the mycological cure was achieved up till day $90^{\text {th }}$. The prevalence of $M$. canis infestation was $31 \%$. The breed wise prevalence was highest in Persian cats as compared to Siamese, and local breed and the prevalence were also higher in young ones as compared to old age cats. Moreover, the calculation of efficacy revealed that griseofulvin was the best drug among the three drugs used.

Keywords: Dermatophytosis; Griseofulvin; Ketoconazole; Ringworm; Terbinafine

\section{Introduction}

Dermatophytosis is the most common contagious and fungal infection in cats, and there are almost 50 species of fungi which are pathogenic for animals throughout the world. Dermatophytosis is a superficial skin 
infection of the keratinized tissues including nails, claws, hairs and stratum corneum of skin. The fungi that cause these infections are known as dermatophytes. Three genera of fungi cause dermatophytosis which are Epidermophyton, Microsporum and Tricophyton [1]. They can be divided into three groups on the basis of natural habitat which are Geophilic dermatophytes which inhabit the soil and serve as a source of infection for both animals and humans [2], Anthropophilic dermatophytes found mainly in humans and usually infect the humans but less commonly animals [3, 4], and Zoophilic dermatophytes found mainly in animals but are capable of infecting other animals and human beings $[5,6]$. These pathogenic fungi are found worldwide, and all domestic animals are susceptible to this fungus. But the most important is Microsporum with species like M. canis, Microsporum gypseum, Microsporum nanum and in cats 98\% infection is caused by $M$. canis $[7,8]$. Dermatophytosis (ringworm) also carries zoonotic importance that infects the humans and infected $9 \%$ of USA's human population at the end of the 1980s [9]. Cats represent the primary source of infection to people, and $20 \%$ of human diseases can be result of close contact with cats and dogs $[10,11]$. Dermatophytosis has a broad spectrum of hosts, but the cat represents the most effective carriers due to high frequency of asymptomatic infections [12].

As the cat is an asymptomatic carrier of dermatophytes and its habit to sleep on beds and divans that prone the human to get this infection [13]. In these places' spores shed by infected animals are difficult to be removed and can remain viable in the environment for up to 18 months. The cats affected by $M$. canis may undergo spontaneous remission, but the infection can be persistent for 18 months to 4 years [13]. Lesions are most commonly on the head, ears, nails, and tail. The classic symptom is small, round lesion that is devoid of hair and will often have scaly skin in the center. Cats of any age can suffer from dermatophyte infection, but ringworm infection is more frequent in young because older animals are less susceptible and if previously exposed to dermatophytosis, have developed immunity [7].

Many antifungal drugs like griseofulvin, ketoconazole, enilconazole, itraconazole, terbinafine, lufenuron, etc. are commonly used worldwide $[14,15]$. Griseofulvin is a fungistatic antifungal agent that inhibits the nucleic acid synthesis and cell mitosis metaphases by interfering with the functions of spindle microtubules [16]. It is used as oral administration in tablet formulation which is reportedly safe for use in puppies and kittens [17].

Oral treatment with Terbinafine is reported to be effective. It is fungicidal that suppresses the biosynthesis of ergosterol through inhibition of the fungal enzyme squaline epoxidase [18]. Ketoconazole is also fungicidal and also effective for the treatment of dermatophytosis in cats [18]. It is available in market in tablets, ointments, creams and shampoos formulations [19]. Itraconazole is triazole derivative that works by altering fungal cell membrane permeability through inhibition of ergosterol synthesis. At low doses, itraconazole is fungistatic and at higher dose it is fungicidal [20].

Keeping in view the importance of dermatophytosis in cats and degree of damage they cause, the present study was designed to evaluate the comparative efficacy of three most common medicines like griseofulvin, terbinafine, and ketoconazole to determine their effectiveness and to check the prevalence of dermatophytosis in cats.

\section{Materials and methods Study area}

In the present study, the presence of $M$. canis was studied in pet cats in the area of district Lahore. For the collection of samples three most busy clinics of Lahore district were 
selected randomly (Pets care and cure clinic Model town, Pet center University of Veterinary and Animal Sciences Lahore, and Pet care clinic Akbar chowk). A trial of three most commonly available medicines, i.e. griseofulvin, ketoconazole and terbinafine in Pakistan was conducted.

\section{Experimental design}

A total number of 200 animals were examined during a period of 3 months from the clinics in district Lahore. The samples were collected from all the cats brought to the clinics. The animals positive for the dermatophytosis were categorized into three groups named, group A, B and C which were comprised of five animals each. Group A animals were treated with Griseofulvin, group B with Ketoconazole, group C with Terbinafine.

\section{Clinical signs}

The cats were examined for clinical signs and symptoms depicted with an infestation. The signs included, round lesions devoid of hairs small pustules, erythema, crusts, scales, itching and patches of alopecia on head, ears, tail, and feet and sometimes the whole body involved. All the positive cats showed above mentioned signs. The most prominent signs recorded were, round lesions devoid of hairs and alopecia on head, ears, tail, and feet (Fig. 1).

\section{Sample collection and preparation}

The animal and equipment were prepared before sample collection. Area of the head, ears, and tail which are the most common sites of infection in dermatophytosis was disinfected with $70 \%$ ethyl alcohol. Sample collection was performed by using sterilized tweezers and scalpel. Hairs (broken, frayed, twisted or hair with healthy appearance) were wrested with tweezers from the edges and center of the lesions. The scales were collected with a scalpel after the lesion scratching $[21,22]$. The samples were labeled for their identification. Then hair and scale samples were cleared by clearing agent, i.e., chloral lactophenol which can break the tissue and released the spores from the hairs and scale sample for identification and a drop of methylene blue was added on slide to get a clear view. A coverslip was placed on the hair and scale sample and the slide was allowed to stand for 24 hours at room temperature which was stabilized the spores on the slide. Preparation was observed under microscope for identification of spores.

\section{Fungal culture}

For fungal culture, standardized [23] was utilized. The area of head, ears and tail was disinfected with $70 \%$ ethyl alcohol as in microscopic technique, to remove surface adhering organisms. Samples were collected with the help of sterilized tooth brushing technique $[23,24]$. With this technique, each cat was brushed vigorously to ensure hairs trapped in the bristles of the toothbrush and the areas mentioned above were brushed twice. Fungal culture was performed by pressing the bristles of the brush on to the plates of Mycobiotic agar containing Sabouraud's dextrose agar, chloramphenical $(0.05 \mathrm{~g})$ and cycloheximide $(0.5 \mathrm{~g})$ and incubated at $28{ }^{\circ} \mathrm{C}$ for $2-5$ weeks [25]. $M$. canis was identified by its macro and microscopic features (Fig. 2), following the criteria published by [26].

\section{Identification and characterization of Microsporum canis}

For identification of $M$. canis, the slide culture method described by Harris [27] was followed. Petri dishes, microscopic slides, and coverslips were sterilized before preparation of slide culture. A small square block $1 \mathrm{~cm}$ square from a plate of mycobiotic agar was taken with a sterile spatula and then placed it in the center of slide. Then a small amount of suspected dermatophyte was taken and inoculated on the solid medium. After that put a coverslip on it and left a piece of cotton soaked with water in the bottom of petri dish to provide the humidity which prevented the media from dehydration. Then 
incubated the petri dish at $25-28{ }^{\circ} \mathrm{C}$. When growth took place, another sterilized microscopic slide was taken and put a drop of lactophenol blue dye in the center of the slide and took the coverslip from the grown slide culture and mounted it on the drop of dye. After fixation of the coverslip, the slide culture was seen under low and medium magnification for identification of the reproductive structures, i.e., microconidia, macroconidia, and spiral hyphae of the required dermatophyte (Fig. 3). M. canis was identified by its macro and microscopic features, following the criteria published by [26].

\section{Medication protocol}

The animals positive for the dermatophytosis were treated according to their groups as already mentioned. In group A, griseofulvin (Fungivin, Ethical Laboratories Pvt. Ltd) was given orally at dose rate of $50 \mathrm{mg} / \mathrm{kg}$ body weight $(250 \mathrm{mg})$ for 4-6 weeks in the form of tablet [28, 29]. Group B animals were treated with ketoconazole (Conaz, Atco Laboratories Ltd) at a dose rate of $10 \mathrm{mg} / \mathrm{kg}$ body weight (50 mg) orally for 4-6 weeks in the form of tablet $[18,30]$. Group $\mathrm{C}$ animals were treated with terbinafine (Terbin, Martin Dow Pharmaceuticals, Pakistan, Ltd) at dose rate of $30 \mathrm{mg} / \mathrm{kg}$ body weight (125 mg) orally for 4-6 weeks [31-33]. Samples of all above groups were collected at 0, 15, 30, 45, 60, 75 and 90 days. Mycological cure was obtained on the basis of scoring system for assessment of lesion severity and with two consecutive negative cultures $[20,28,34]$.

\section{Statistical analysis}

The prevalence of $M$. canis infestation was calculated by using the formula as described by [35]. The data obtained as a result of different medications of various groups were analyzed according to the completely randomized design through analysis of variance technique and means were compared for significance according to the least significant difference [36].

\section{Results}

Prevalence Microsporum canis in different sex, breed, and age

Prevalence of $M$. canis infestation was recorded in pet cats of different sex, breed and age. It was noted that out of the total 200 animals, 62 were found positive whereas, 138 were negative for Microsporum canis infestation the prevalence was $31 \%$ (Table 1). Moreover, 62 positive cases $40.32 \%(n=25)$ were recorded in male cats and $59.67 \%$ $(n=37)$ in female cats.

The prevalence of dermatophytosis was also calculated in individual breeds and genderwise and it was found that 38 were positive with $M$. canis out of 96 Persian cats. However, in Siamese 18 out of total 66 cats tested were recorded positive, whereas, in the local breeds 6 were positive out of 38 (Table 2). Therefore, prevalence was $39.58 \%$ in Persian, $27.27 \%$ in Siamese and $15.78 \%$ in local breeds. Moreover, the data of gender revealed 25 positive cases from 80 male cats and 37 from 120 female cats presented in the clinics irrespective of their breeds. The prevalence in male and female cats was found to be almost equal that was $31.25 \%$ and $30.83 \%$ respectively (Table 2 ).

The prevalence of $M$. canis calculated in cats in relation to their age revealed that 90 cats were tested at 12 months of age, it was noted 38 cats positive with $M$. canis. Whereas 1-5 years, 50 cats were tested and 14 found positive (Table 3). Moreover, in 5-8 years 10 were positive out of 60 presented in the clinics (Table 3). Therefore, the prevalence was recorded $42.22 \%$ in 12 months, $28 \%$ in $1-5$-year, and $16.66 \%$ in $5-8$ years of age in cats (Table 3).

\section{Therapy and antifungal susceptibility profile of Microsporum canis}

The cats found positive for the $M$. canis infestation were categorized into three groups named, treatments $\mathrm{A}, \mathrm{B}$, and $\mathrm{C}$. In treatment A the animals were treated with griseofulvin, $\mathrm{B}$ with ketoconazole and $\mathrm{C}$ with terbinafine. 
The efficacy of the above-mentioned drugs was determined on day 15, 30, 45, 60, 75 and 90 during the study trial. In all the three treatments the medicines were administered orally to the cats. For this all the drugs were given to the animals of three mentioned groups until achieved the mycological cure. The efficacy of the three-drug trials was calculated numerically. In treatment $\mathrm{A}$, the efficacy of griseofulvin was found to be $25 \%$ at day $15,80 \%$ at day 30 and $100 \%$ at day 45 and medication were stopped because mycological cure was achieved at day 45 . In treatment B ketoconazole was used, the recorded efficacy was $10 \%$ on day $15,20 \%$ on day $30,40 \%$ on day $45,60 \%$ on day 60 , $70 \%$ on day 75 whereas it was $85 \%$ on day 90 when the drug trials were completed. However, in treatment $\mathrm{C}$, the efficacy of terbinafine was recorded $20 \%, 45 \%, 75 \%$ and $100 \%$ on day 15, 30, 45 and 60 respectively. Statistically griseofulvin has no significant difference with terbinafine while significant difference $(\mathrm{P}<0.05)$ was observed among griseofulvin, ketoconazole, and terbinafine.

\section{Discussion}

The cat is commonly kept as a pet for its fine nature, nice learning and a good sense of essence and worldwide population of cats exceeds 500 million [37]. Cats serve as a reservoir of $M$. canis and since no work has been done to determine the prevalence of dermatophytosis and chemotherapy against M. canis infestation in pet cats in Pakistan $[22,38]$. Keeping in view the importance of M. canis infestation in cats and degree of damage they cause, the present study was designed to determine the prevalence of $M$. canis infestation in pet cats (Felis catus) in the area of district Lahore to establish their efficacy $[2,11]$.

During the present study a total of 200 cases were recorded, among them, 62 (31\%) were found positive whereas, 138 were negative for Microsporum canis infestation (Table 1). The finding of present investigation was lower as compared to the former reports that the prevalence of Microsporum canis infestation in cats was $53.5 \%$ and $55.9 \%$ respectively because of environmental and managemental conditions [25, 39]. The higher percentage reported by these workers may be due fact that they worked on both pet and stray cats and our study was conducted only on pet cats because pet animal is in good condition as compared to stray one. Out of the total 62 positive cases in cats, $31.25 \%$ and $30.83 \%$ prevalence was recorded in male and female cats, and the similar findings were recorded by $[25,40]$.

In the present study, the prevalence of $M$. canis infestation was recorded in three different breeds of cats which were kept as pets and brought to the clinics. Breed wise the highest prevalence was recorded in Persian cats $(39.58 \%)$, and the second-highest was recorded in Siamese cats $(27.27 \%)$, whereas the lowest prevalence of $M$. canis was recorded in local breed $(21.05 \%)$ (Table 2). These findings are different as compared with the results reported by [41], according to report the prevalence of $M$. canis infestation in Siamese cat was bit higher than the Persian cats $(14.3 \%$, and $12.5 \%$ respectively), because Persian has long hair coat and long hairs trap more spores and has fungal friendly environment as compared to short hair cat and local breed showed lowest result of prevalence percentage because this breed is immunologically more competent as compared to exotic breeds. While $[34,42]$ had similar findings to our study that the prevalence of $M$. canis infestation in long hair cats was more as compared to short hair cats.

In this study cats received in the clinics were divided into three age groups (1 month to 12 months, 1-5 years, and above 5 years), and the total number of cats which were studied ranged from 1 month to 8 years of age. It was observed that a maximum prevalence of Microsporum canis infestation 
was recorded in young cats ranging from 1 to 12 months of age $(42.22 \%)$ and the secondhighest prevalence was in age group from 15 year $(28 \%)$, whereas the lowest prevalence was recorded in 5-8 years of cats (Table 3). The same findings were recorded by $[25,41]$ that prevalence of $M$. canis infestation mostly occurs in cats less than 1 year. The highest prevalence of $M$. canis in the age group up to 12 months of age indicated that such cats were not immunologically competent to protect themselves against the disease due to their young age and it also depended upon the degree of interaction in the fellow cats present in the same home. The second highest prevalence in 1-5 years of age could be due to the fact that such cats had contact with stray cats as they were let outdoors by the clients. The lowest prevalence was recorded in maximum age group of cats above 5 years indicating development of resistance and competent immunological response against the disease and this is similar to the findings of [41] that the prevalence of $M$. canis in cats with age range from 1 month to more than 5 years.

Cats positive to $M$. canis were also observed for a depiction of clinical signs. The signs recorded were round lesions devoid of hair, small pustules were often found in lesion and patches of alopecia with erythema and greyscales (Fig. 1). Lesions were most common on the head, ears, and tail, it often spread across the face, lips, chin or nose and the same findings were observed by [43]

In treatment $\mathrm{A}$, griseofulvin was given orally at the dose rate of $50 \mathrm{mg} / \mathrm{kg}$ body weight once in a day up to a 4-6 week in the form of tablets. The efficacy of griseofulvin was observed by collecting the samples on day $15,30,45,60,75$ and 90 after the commencement of treatment, which was $25 \%, 80 \%$, and $100 \%$ respectively on day 15 , 30 and 45 and the further treatment was stopped when $100 \%$ results and mycological cure were obtained (Table 4), which is in agreement with the findings of [44], it showed that efficacy of griseofulvin was $100 \%$ on day 41 and obtained mycological cure. Similarity, [28] used griseofulvin along with $2 \%$ miconazole shampoo twice weekly and obtained mycological cure $100 \%$ at day 42.

Whereas treatment $\mathrm{B}$, ketoconazole was given orally at a dose rate of $10 \mathrm{mg} / \mathrm{kg}$ bodyweight for 4-6 weeks in the form of tablet. The efficacy of ketoconazole was observed by collecting the samples on day $15,30,45,60,75$ and 90 after the commencement of treatment, which was $10 \%, 20 \%, 40 \%, 60 \%, 70 \%$ and $85 \%$ respectively (Table 4), which is in agreement with the findings of [45], he obtained successful result only in 8 cats out of 12 which was successfully treated with resolution of lesions and mycological cure after 2 to 10 weeks of drug trial. According to [18] also found the same result in his study but he used ketoconazole along with food to obtain an optimal absorption.

However, treatment $\mathrm{C}$, terbinafine was given orally at the dose rate of $30 \mathrm{mg} / \mathrm{kg}$ body weight once in a day up to a 4-6 week in the form of tablets. The efficacy of terbinafine was observed by collecting the samples on day $15,30,45,60,75$ and 90 after the commencement of treatment, which was $20 \%, 45 \%, 75 \%$ and $100 \%$ respectively on day 15, 30, 45 and 60 because we obtained mycological cure at day 60 (Table 4) which is in agreement with the findings of [32] the investigation finds that terbinafine in cats and showed that efficacy of terbinafine was $100 \%$ on day 60. Similarly, [46] studied that terbinafine showed mycological cure on day 63. Moreover, the present study indicated that the efficacy of ketoconazole was not more than $85 \%$ while $100 \%$ was recorded in griseofulvin and terbinafine.

Griseofulvin was found to be a most effective medicine to treat the $M$. canis infestation as maximum efficacy of $100 \%$ was recorded on 
day 45 , which was significantly higher than terbinafine which showed $100 \%$ efficacy on day 60 and much higher than ketoconazole which showed $85 \%$ efficacy after the completion of whole drug trial. In this study, we found that there was no significant difference in the efficacy between the groups treated with griseofulvin and terbinafine but found significant difference $(\mathrm{P}<0.05)$ between griseofulvin and ketoconazole and was a significant difference $(\mathrm{P}<0.05)$ between terbinafine and ketoconazole at the end of trial statistically but overall all the drugs has a significant effect against $M$. canis infestation in cats.

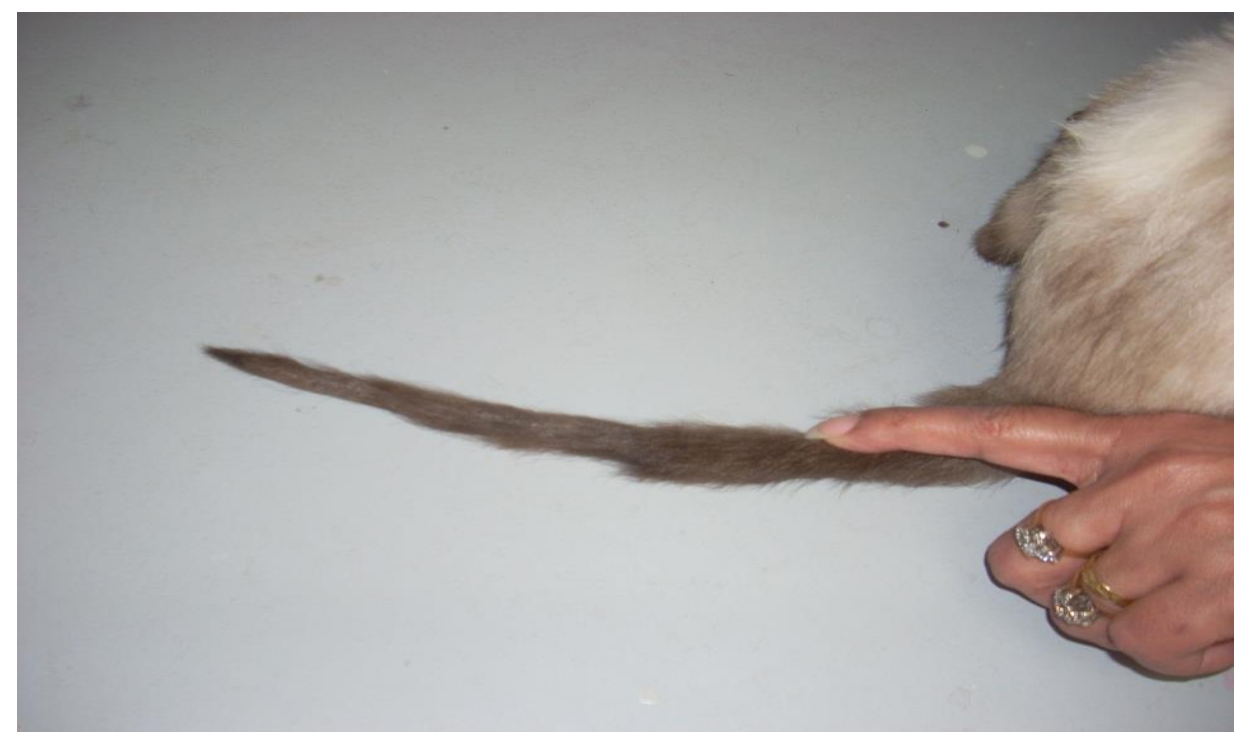

Figure 1. The cat's tail having complete alopecia

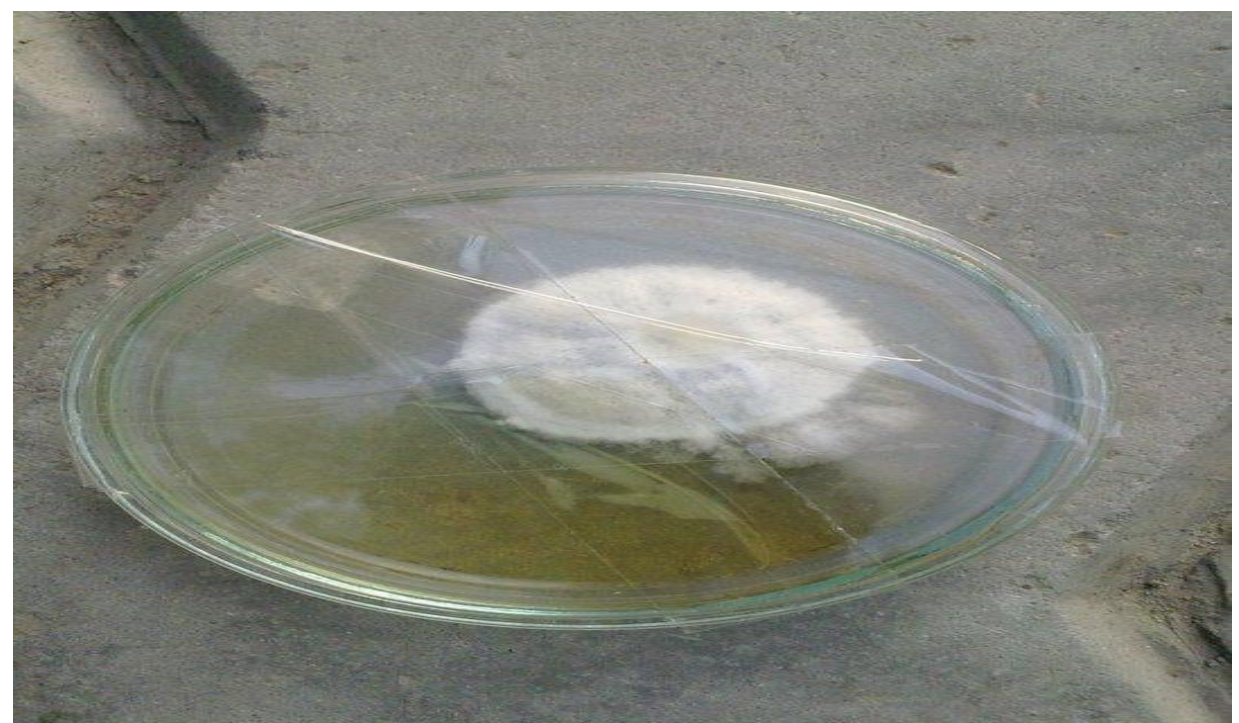

Figure 2. Fungal colony of Microsporum canis 


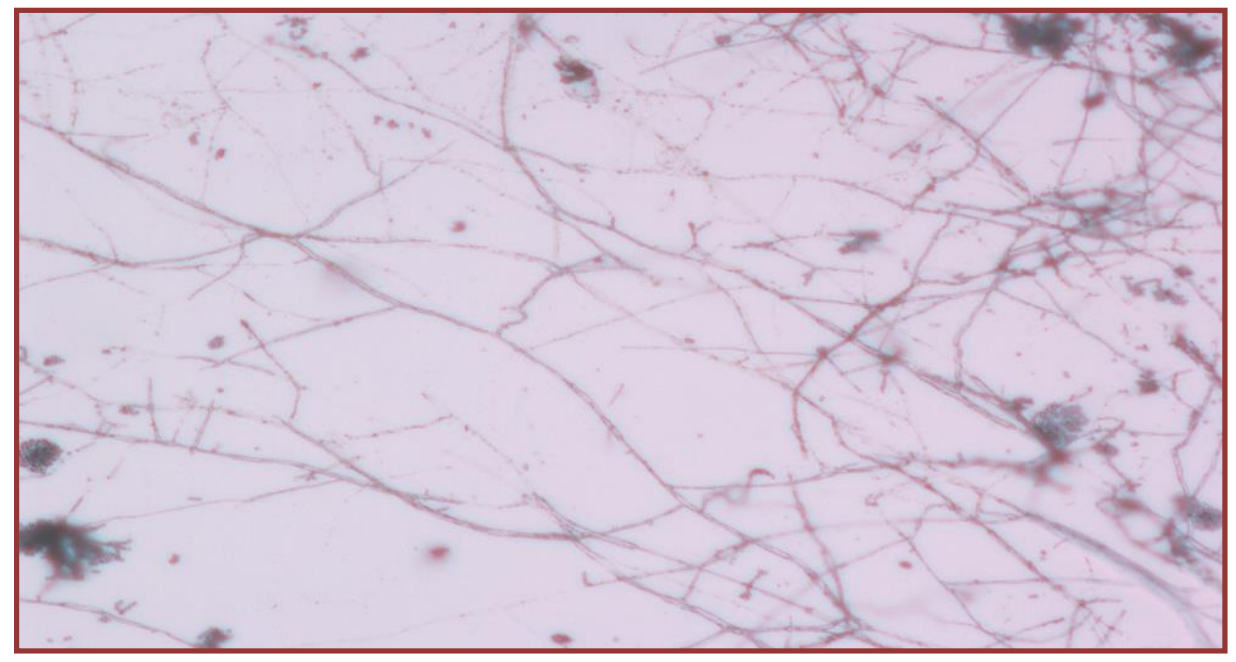

Figure 3. Microscopic structure of Microsporum canis

Table 1. Prevalence of Microsporum canis infestation in Pet Cats

\begin{tabular}{|c|c|c|c|}
\hline $\begin{array}{c}\text { No. of cats } \\
(\mathbf{n})\end{array}$ & $\begin{array}{c}\text { Positive with } \\
\text { Microsporum canis } \\
(\mathbf{n})\end{array}$ & $\begin{array}{c}\text { Negative with } \\
\text { Microsporum canis } \\
(\mathbf{n})\end{array}$ & $\begin{array}{c}\text { Prevalence of } \\
\text { Microsporum canis } \\
(\%)\end{array}$ \\
\hline 200 & 62 & 138 & 31 \\
\hline
\end{tabular}

Table 2. Prevalence of Microsporum canis infestation in different breeds and sex

\begin{tabular}{|c|c|c|c|c|c|}
\hline \multirow{2}{*}{ Particulars } & \multicolumn{3}{|c|}{ Breeds } & \multicolumn{2}{c|}{ Sex } \\
\cline { 2 - 6 } & Persian & Siamese & Local & Male & Female \\
\hline $\begin{array}{c}\text { Dermatophytosis } \\
\text { positive (n) }\end{array}$ & 38 & 18 & 6 & 25 & 37 \\
\hline $\begin{array}{c}\text { Dermatophytosis } \\
\text { negative (n) }\end{array}$ & 58 & 48 & 32 & 55 & 83 \\
\hline Total (n) & 96 & 66 & 38 & 80 & 120 \\
\hline Prevalence (\%) & 39.58 & 27.27 & 15.78 & 31.25 & 30.83 \\
\hline
\end{tabular}

Table 3. Prevalence of Microsporum canis infestation in different age groups

\begin{tabular}{|c|c|c|c|}
\hline Particulars & Upto12 months & 1 year - 5 year & 5 year - 8 year \\
\hline $\begin{array}{c}\text { Microsporum canis } \\
\text { Positive (n) }\end{array}$ & 38 & 14 & 10 \\
\hline $\begin{array}{c}\text { Microsporum canis } \\
\text { negative (n) }\end{array}$ & 52 & 36 & 50 \\
\hline Total (n) & 90 & 50 & 60 \\
\hline Prevalence $(\%)$ & 42.22 & 28 & 16.66 \\
\hline
\end{tabular}


Table 4. Post oral treatment efficacy of Griseofulvin, Ketoconazole and Terbinafine against Microsporum canis infection in cats. Mean values followed by the same letter in the same column do not vary significantly $(P<0.05)$

\begin{tabular}{|c|c|c|c|c|c|c|c|}
\hline $\begin{array}{c}\text { Treat } \\
\text { ments }\end{array}$ & Drugs & $\begin{array}{c}\text { Efficacy } \\
\text { at day 15 } \\
(\mathbf{\%})\end{array}$ & $\begin{array}{c}\text { Efficacy } \\
\text { at day 30 } \\
(\mathbf{\%})\end{array}$ & $\begin{array}{c}\text { Efficacy } \\
\text { at day 45 } \\
(\mathbf{\%})\end{array}$ & $\begin{array}{c}\text { Efficacy } \\
\text { at day 60 } \\
(\mathbf{\%})\end{array}$ & $\begin{array}{c}\text { Efficacy } \\
\text { at day 75 } \\
(\mathbf{\%})\end{array}$ & $\begin{array}{c}\text { Efficacy } \\
\text { at day 90 } \\
(\mathbf{\%})\end{array}$ \\
\hline A & Griseofulvin & $25^{\mathrm{a}}$ & $80^{\mathrm{a}}$ & $100^{\mathrm{a}}$ & $100^{\mathrm{a}} *$ & $100^{\mathrm{a}} *$ & $100^{\mathrm{a}} *$ \\
\hline $\mathrm{B}$ & Ketoconazole & $10^{\mathrm{c}}$ & $20^{\mathrm{c}}$ & $40^{\mathrm{c}}$ & $60^{\mathrm{c}}$ & $70^{\mathrm{c}}$ & $85^{\mathrm{c}}$ \\
\hline $\mathrm{C}$ & Terbinafine & $20^{\mathrm{ab}}$ & $45^{\mathrm{b}}$ & $75^{\mathrm{b}}$ & $100^{\mathrm{a}}$ & $100^{\mathrm{a}} *$ & $100^{\mathrm{a}} *$ \\
\hline
\end{tabular}

$*=$ NO further treatment when achieved $100 \%$ efficacy

\section{Conclusion}

The cat is commonly kept as a pet all over the world. The dermatophyte $M$. canis is the most common fungal agent of dogs and cats. In the present study, the prevalence of $M$. canis was recorded in pet cats in the area of district Lahore. It was found that $M$. canis infestation having moderate prevalence in domestic cats and Griseofulvin is the most effective and readily available product in Pakistan. Moreover, there is no predilection of sex, whereas, the high prevalence was found in young and long coat cats.

\section{Authors' contributions}

Conceived and designed the experiments: KU Rehman \& AK Mahmood, Performed the experiments: MI Saleem \& A Qudus, Analyzed the data: M Akbar \& MT Naveed, Contributed materials/ analysis/ tools: A Nadeem. M Tanveer, A Noor \& M Attique, Wrote the paper: KU Rehman.

\section{References}

1. Baghza MN (2016). Isolation and Identification of Potential Zoonotic Dermatophytes from Domestic Camels in Dhamar Area, Yemen. American $J$ of Health Res 4(3): 46.

2. Ilhan Z, Karaca M, Ekin IH, Solmaz H, Akkan HA \& Tutuncu M (2016). Detection of seasonal asymptomatic dermatophytes in Van cats. Brazilian $J$ of Microbiol 47(1): 225-230.

3. Baumgardner DJ (2017). Fungal Infections From Human and Animal Contact. $J$ of Patient-Centered Res and Rev 4(2): 78-89.
4. de Hoog GS, Dukik K, Monod M, Packeu A, Stubbe D, Hendrickx M, \& Gräser Y (2017). Toward a Novel Multilocus Phylogenetic Taxonomy for the Dermatophytes. Mycopathol 182(1-2): 531.

5. Gräser Y, Monod M, Bouchara JP, Dukik K, Nenoff P, Kargl A \& De Hoog, S (2018). New insights in dermatophyte research. Medical Mycol. Narnia.

6. Faway É, Lambert de Rouvroit C \& Poumay Y (2018). In vitro models of dermatophyte infection to investigate epidermal barrier alterations. Experimental Dermatol. John Wiley \& Sons, Ltd (10.1111).

7. Nweze EI \& Eke IE (2018). Dermatophytes and dermatophytosis in the eastern and southern parts of Africa. Medical Mycol. Narnia.

8. Lipner SR \& Scher RK (2015). Onychomycosis: Diagnosis and therapy. In Medical Mycology: Current Trends and Future Prospects (pp. 28-57). CRC Press.

9. Moriello, K. (2014). Feline dermatophytosis: aspects pertinent to disease management in single and multiple cat situations. Journal of Feline Medicine and Surgery, 16(5): 419-431.

10. Thompson, R. C. A. (2000, November 1). Giardiasis as a re-emerging infectious disease and its zoonotic potential. Inter $J$ for Parasitol Pergamon.

11. Iqbal N (2017). Prevalence of gastrointestinal parasites in Faisalabad and comparative efficacy of Ivermectin and 
Albendazole. Pure and Appl Biol 6(2): 499-504.

12. Chermette R, Ferreiro L, \& Guillot J (2008). Dermatophytoses in animals. Mycopathologia. Springer Netherlands, November 14.

13. Mancianti F, Pedonese F, Millanta F \& Guarnieri L (1999). Efficacy of oral terbinafine in feline dermatophytosis due to Microsporum canis. $J$ of Feline Medicine and Surgery 1(1): 37-41.

14. Magagnin CM, Stopiglia CD, Vieira FJ, Heidrich D, Machado M, Vetoratto G \& Scroferneker ML (2011). Antifungal susceptibility of dermatophytes isolated from patients with chronic renal failure. An Bras Dermatol.

15. Frymus T, Gruffydd-Jones T, Pennisi MG, Addie D, Belák S, Boucraut-Baralon C \& Horzinek MC (2013). Dermatophytosis in Cats. Journal of Feline Medicine and Surgery 15(7): 598-604.

16. Nardoni S, Mugnaini L, Papini R, Fiaschi M \& Mancianti F (2013). Canine and feline dermatophytosis due to microsporum gypseum: A retrospective study of clinical data and therapy outcome with griseofulvin. $J$ de Mycologie Medicale 23(3): 164-167.

17. Moriello, K. (2014). Feline dermatophytosis: aspects pertinent to disease management in single and multiple cat situations. J of Feline Med and Surgery 16(5): 419-431.

18. Rochette F, Engelen M \& Vanden Bossche $\mathrm{H}$ (2003, February). Antifungal agents of use in animal health - Practical applications. J of Vet Pharmacol and Therapeutics.

19. Rotta I, Sanchez A, Gonçalves PR, Otuki MF \& Correr CJ (2012). Efficacy and safety of topical antifungals in the treatment of dermatomycosis: A systematic review. British J of Dermatol.

20. Colombo S, Cornegliani L \& Vercelli A (2001). Efficacy of itraconazole as a combined continuous/pulse therapy in feline dermatophytosis: Preliminary results in nine cases. Vet Dermatol 12(6): 347-350.

21. Duarte A, Castro I, Pereira da Fonseca IM, Almeida V, Madeira de Carvalho LM, Meireles J \& Vaz Y (2010). Survey of infectious and parasitic diseases in stray cats at the Lisbon Metropolitan Area, Portugal. J of Feline Medicine and Surgery 12(6): 441-446.

22. Rogério E, Dison C, Cansi R \& Demo A (2011). Acta Scientiae Veterinariae. Acta Scientiae Veterinariae 39(3): 982.

23. Mackenzie DWR (1963). "Hairbrush diagnosis" in detection and eradication of non-fluorescent scalp ringworm. British Medical J 2(5353): 363-365.

24. Hay RJ (2016). Fungal Infections of the Hair. In Antibiotic and Antifungal Therapies in Dermatology 187-202.

25. Yahyaraeyat R, Shokri H, Khosravi AR, Soltani M, Erfanmanesh A \& Nikaein D (2009). Occurrence of animals dermatophytosis in Tehran, Iran. World $J$ of Zool 4(3): 200-204.

26. George LK (2017). Dermatophytes: Their Recognition and Identification. The American J of Tropical Med and Hygiene 20(4): 653-654.

27. Harris JL (1986). Modified method for fungal slide culture. $J$ of Clin Microbiol 24(3): 460-461.

28. Sparkes AH, Robinson A, MacKay AD \& Shau SE (2000). A study of the efficacy of topical and systemic therapy for the treatment of feline Microsporum canis infection. $J$ of Feline Medicine and Surgery 2(3): 135-142.

29. Aneke C, Otranto D, Cafarchia C, Aneke CI, Otranto D \& Cafarchia C (2018). Therapy and Antifungal Susceptibility Profile of Microsporum canis. $J$ of Fungi 4(3): 107.

30. Seyedmousavi S, Wiederhold NP, Ebel F, Hedayati MT, Rafati H \& Verweij PE (2018). Antifungal use in veterinary practice and emergence of resistance. In Emerging and Epizootic Fungal Infections in Animals (pp. 359-402). Cham: Springer International Publishing. 
31. Debnath C, Mitra T, Kumar A \& Samanta I (2016). Detection of dermatophytes in healthy companion dogs and cats in eastern India. Iranian J of Vet Res 17(1): 20-24.

32. Caretta G, Mancianti F \& Ajello L (1989). Dermatophytes and Keratinophilic Fungi in Cats and Dogs Dermatophyten und keratinophile Pilze bei Katzen und Hunden. Mycoses 32(12): 620-626.

33. Caretta G, Mancianti F \& Ajello L (2009). Dermatophytes and Keratinophilic Fungi in Cats and Dogs Dermatophyten und keratinophile Pilze bei Katzen und Hunden. Mycoses 32(12): 620-626.

34. Puls C, Johnson A, Young K, Hare J, Rosenkrans K, Young L \& Moriello K (2018). Efficacy of itraconazole oral solution using an alternating-week pulse therapy regimen for treatment of cats with experimental Microsporum canis infection. $J$ of Feline Medicine and Surgery.

35. Thrusfield M (1995). Veterinary Epidemiology. Oxford.

36. Fox, R. A., Steel, R. G. D., \& Torrie, J. H. (2006). Principles and Procedures of Statistics with Special Reference to the Biological Sciences. The Incorporated Statistician 11(3): 170.

37. Seidensticker J \& Lumpkin S (2016). Cats in Question: The Smithsonian Answer Book.

38. Moriello, K. A. (2003). Zoonotic skin diseases of dogs and cats. Animal Health Res Rev 4(02): 157-168.
39. Omran AN, Hashemi SJ \& Hashemi F (2010). Epidemiology of superficial and cutaneous mycosis in 5500 suspected patients in Tehran. Tehran Uni Med J.

40. Mignon BR \& Losson BJ (1997). Prevalence and characterization of Microsporum canis carriage in cats. Medical Mycol.

41. Cabañes FJ, Abarca ML \& Bragulat MR (1997). Dermatophytes isolated from domestic animals in Barcelona, Spain. Mycopathologia.

42. Moriello KA \& DeBoer DJ (1995). Efficacy of griseofulvin and itraconazole in the treatment of experimentally induced dermatophytosis in cats. Journal of the American Vet Medical Association.

43. Bond R (2010). Superficial veterinary mycoses. Clinics in Dermatol.

44. Balda AC, Otsuka $M$ \& Larsson CE (2007). A clinical trial using griseofulvin and terbinafine in the treatment of canine and feline dermatophytosis. Ciência Rural 37: 750-754.

45. Medleau L \& Chalmers SA (1992). Ketoconazole for treatment of dermatophytosis in cats. $J$ of the American Vet Medical Assoc 200(1): 77-78.

46. Castanon-Olivares LR, Manzano-Gayosso P, Lopez-Martinez R, De la RosaVelazquez IA \& Soto-Reyes-Solis E (2001). Effectiveness of terbinafine in the eradication of Microsporum canis from laboratory cats. Mycoses 44(3-4): 95-97. 